DOI: 10.18468/letras.2018v8n2.p33-46

ANÁLISE SEMIOLINGUÍSTICA NA CONSTITUIÇÃO DE SENTIDO E

ENCENAÇÃO ARGUMENTATIVA DA CHARGE JORNALÍSTICA

\author{
Janicleide Vidal Maia ${ }^{1}$ \\ Avanúzia Ferreira Matias ${ }^{2}$
}

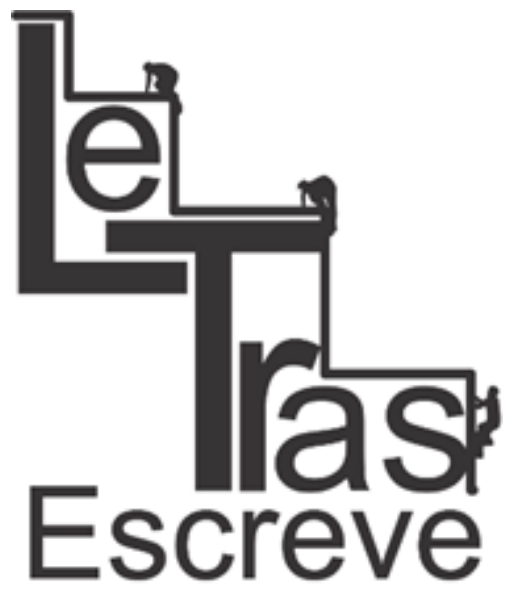

(ISSN 2238-8060)

\title{
Introdução
}

RESUMO:O objetivo desse trabalho é analisar charges jornalísticas sob o aporte teórico da Teoria Semiolinguística de Patrick Charaudeau (2007, 2009). Como procedimento metodológico foram selecionadas duas charges jornalísticas no intuito de buscar compreender como o chargista, inspirado na política, elabora sua crítica a partir da encenação argumentativa. A análise revelou que esse jogo enunciativo, fruto da interação dialética entre discurso e sociedade, visa ao julgamento dos fatos sociais políticos por meio do humor satírico e da ironia.

Palavras-chave: Charge jornalística; Teoria semiolinguística; Encenação argumentativa.

ABSTRACT: The objective of this work is to analyze journalistic cartoons under the theoretical contribution of the Semiolinguistic Theory of Patrick Charaudeau $(2007,2009)$. As a methodological procedure, two journalistic cartoons were selected in order to understand how the cartoonist, inspired by politics, elaborates his criticism from the argumentative scenario. The analysis revealed that this enunciative game, fruit of the dialectical interaction between discourse and society, aims at the judgment of the political social facts through satirical humor and irony.

Keywords: Journalistic Charge; Semiolinguistic theory; Argumentative staging.

A linguagem, além de ser uma instituição social, é um veículo de ideologias, ela é mediadora entre os homens e a natureza e entre

\footnotetext{
${ }^{1}$ Doutora em Linguística; professora de Língua Portuguesa e suas respectivas literaturas em escolas da Rede Estadual de Ensino do Ceará e na Escola de Gestão Pública; Tutora da UFC Virtual (Universidade Federal do Ceará). Professora no Instituto Brasileiro de Formação de Educadores - Fortaleza. É membro do Grupo de Pesquisa Gelda/CNPQ - Grupo de Estudos Linguísticos em Discurso Autobiográfico; jvidalmaia@gmail.com

${ }^{2}$ Graduada em Letras (UFC) e Pedagogia (Universidade Paulista); especialista em Psicopedagogia clínica e Institucional e em Gestão Pública; mestrado em Linguística e doutorado em Educação Brasileira; membro do Grupo de Pesquisa LER - Linguagem Escrita Revisitada, da Universidade Federal do Ceará. professora de Língua Portuguesa e suas respectivas literaturas (SEDUC-CE); avamatias@gmail.com
}

https://periodicos.unifap.br/index.php/letras

Macapá, v. 8, n. 2, 2 sem., 2018 
os homens e os outros homens (FIORIN, 1988). Ademais, a linguagem é poder (CHARAUDEAU, 2009). Esse poder, todavia, não surge fruto do acaso, é fruto da construção do próprio homem e constitui-se na força que lhe permite agir através dos tempos.

O agir do chargista no mundo denota seu posicionamento diante de um problema social. Para tanto, ele quase sempre recria, através de caricaturas, a imagem de pessoas públicas envolvidas em diversos acontecimentos, como por exemplo os eventos políticos polêmicos.

Nesse trabalho, discorremos, portanto como a charge permite ao seu autor falar do seu mundo subjetivo e do seu mundo exterior, além de perscrutarmos nesse discurso a argumentação em favor das ideias defendidas pelo chargista.

\section{A constituição de sentido na charge}

A charge pode ser compreendida como "um texto visual humorístico que critica uma personagem, fato ou acontecimento político específico. Por focalizar uma realidade específica, ela se prende mais

(ISSN 2238-8060) ao momento, tendo, portanto, uma limitação temporal" (ROMUALDO, 2000, p.21). Esse gênero traz pouca ou, às vezes, nenhuma informação linguística. Portanto, a charge, enquanto mensagem icônica, não será recebida nem decifrada se o leitor não possuir informações necessárias para interpretá-la.

A charge, presente na esfera jornalística, cumpre um papel tanto informativo quanto argumentativo. Portanto, nesse gênero pode estar presente mais de um modo de organização do discurso. Pelo viés informativo, a charge descreve uma situação específica, a critério da intenção do chargista e se inscreve no modo de organização do discurso descritivo. Sob a ótica argumentativa e também subjetiva da 
linguagem, marcando o juízo de valor do chargista, temos o modo de organização do discurso argumentativo.

A esse respeito Aroeira apud Valente (2001, p. 152) afirma:

a parte que eu acho mais importante é o que essa charge vai significar, vai realmente ser. Todos os trabalhos dos chargistas são claramente engajados ideologicamente, todos são contra o neoliberalismo, contra as privatizações, contra o Fernando Henrique, contra a polícia do Rio, contra o governador Garotinho, contra tudo o que pisa no nosso pé diariamente, o que acontece no Brasil todos os dias.

Ao se referir ao contexto sócio-histórico em que Fernando Henrique Cardoso presidia o Brasil e Garotinho governava o Rio de

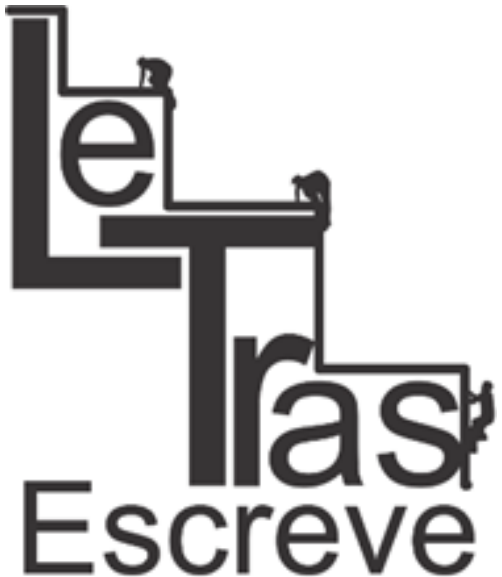

(ISSN 2238-8060)

Janeiro, Aroeira, então chargista do Jornal O Globo, reafirma o caráter argumentativo do texto chárgico. Logo, o chargista ao produzir sua charge, busca o engajamento do leitor de modo a levá-lo a concordar o ponto de vista implícito na charge. Desta feita, no afã de persuadir o leitor é que se sobressai nesse gênero o modo de organização argumentativo do discurso. Isso revela, na charge, a importância do como se diz e não simplesmente o que se diz:

\begin{abstract}
a gente tem que agir rápido, a gente pega os jornais, dá uma lida, já descobre quem é o personagem e sai fazendo a caricatura sem nem pensar o que realmente vai fazer com ele. Isso é comum acontecer. Daí o lque, com essa prática, com a mão coçando, desenha o tempo inteiro, também estou desenhando. Mas a gente faz porque quer realmente dizer alguma coisa, [...] Nós temos conteúdo, exploramos os significados e usamos muito essa brincadeira dos trocadilhos, dos opostos. Eu uso mais texto do que o lque, um cara que gosta de fazer trocadilho só no desenho (AROEIRA apud VALENTE, 2001, p.151).
\end{abstract}

Desse modo, a charge é uma maneira de o chargista recontar a história, não simplesmente registrando o real, mas ressignificandoo(TEIXEIRA, 2005). Assim, a constituição de sentido no texto chárgico 
pode ser compreendido a partir do esquema abaixo:

Quadro 1 - Esquema de constituição do texto chárgico

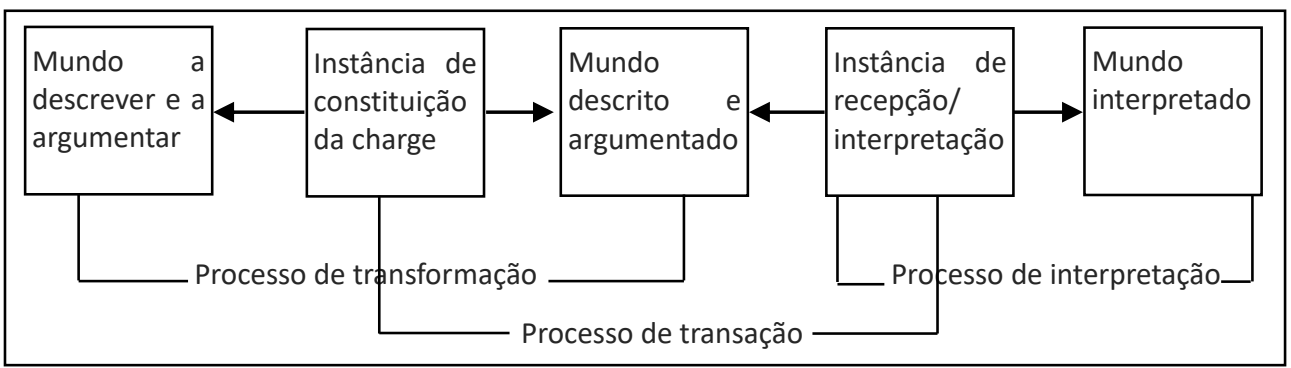

Adaptado de Charaudeau, 2007, p. 23.

O quadro propõe uma reflexão sobre como se dá a constituição do texto chárgico, que parte da instância real para a instância textual. Atrelado a esse processo de transação que culmina na significação do

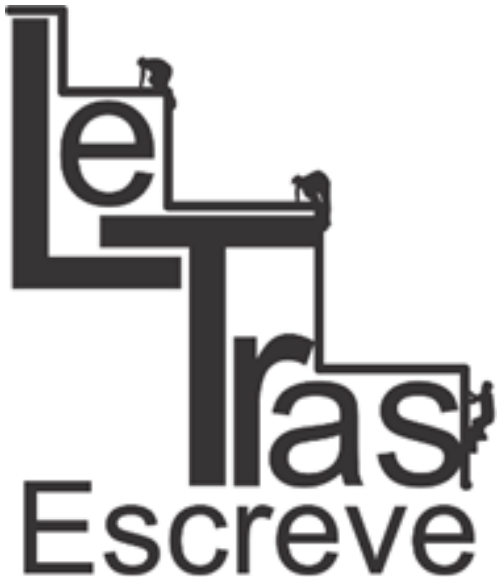
mundo, a partir da instância de recepção, está o processo de interpretação que o leitor realiza ao se deparar com a charge.

$\mathrm{Na}$ análise semiolinguística, o processo de interpretação se dá quando o sujeito interpretante ativa seu conhecimento de mundo e sistematiza a construção de sentido do texto chárgico. Sendo assim, o projeto de fala da charge se desvela por meio de um contrato comunicativo estabelecido entre chargista e leitor da charge.

(ISSN 2238-8060)

\section{A encenação argumentativa}

Charaudeau (2009) destaca que nem toda assertiva é necessariamente argumentativa, portanto afirma que toda assertiva pode ser argumentativa desde que esteja inscrita num dispositivo argumentativo. As assertivas devem se encadear de modo a constituir parte do processo argumentativo, que Charaudeau chama de proposta ${ }^{3}$. No

\footnotetext{
${ }^{3}$ A proposta corresponde ao que, em algumas abordagens da argumentação, se chama de tese.
} 
entanto, ainda se faz necessário que se cumpram mais dois requisitos: primeiro, que o sujeito que argumenta tome posição pela veracidade da proposta (tese) quer seja ele o autor ou não, a proposta deve estar atrelada a uma proposição; segundo, não basta somente que se faça a proposição, é necessário que se garanta uma argumentação; por isso o sujeito argumentante deve dizer por que está de acordo ou não com a proposta (tese), caso seja ele mesmo o autor da proposta (tese) deve fornecer a prova da sua proposta (tese), desenvolvendo o que o autor chama de persuasão. Eis, pois, a composição do dispositivo argumentativo: proposta (tese), proposição e persuasão.

Charaudeau (2009) sintetiza os componentes da lógica argumentativa através da relação argumentativa proposta no esquema que segue:

Quadro 2 - Esquema da relação argumentativa.

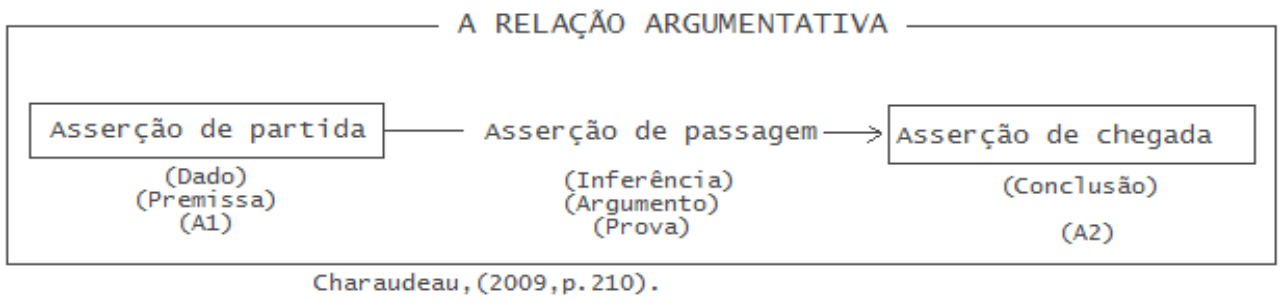

Sendo assim, toda relação argumentativa se constitui de, pelo menos, três elementos: uma asserção de partida (dado, premissa), uma asserção de chegada (conclusão, resultado) e uma ou várias asserções de passagem que permitem passar de uma a outra (inferência, prova, argumento).

Charaudeau (2009) explica que a passagem de A1 para A2 se dá de modo lógico e de maneira relativamente estreita. A inferência que garante a referida passagem entre premissa e conclusão estabelece um vínculo modal que se situa no domínio do possível, do necessário ou do provável. Seguindo nesse processo do nascedouro do 
raciocínio argumentativo, percebemos que os diferentes componentes da lógica argumentativa combinam-se entre si para dar lugar a modos de raciocínio.

Mediante um contrato de comunicação, o sujeito argumentante interage com seu interlocutor emitindo sua proposta sobre o mundo, essa por sua vez, inscreve-se num quadro de questionamento que possa gerar um ato de persuasão. O quadro abaixo resume a encenação argumentativa.

Quadro 3 - Encenação argumentativa

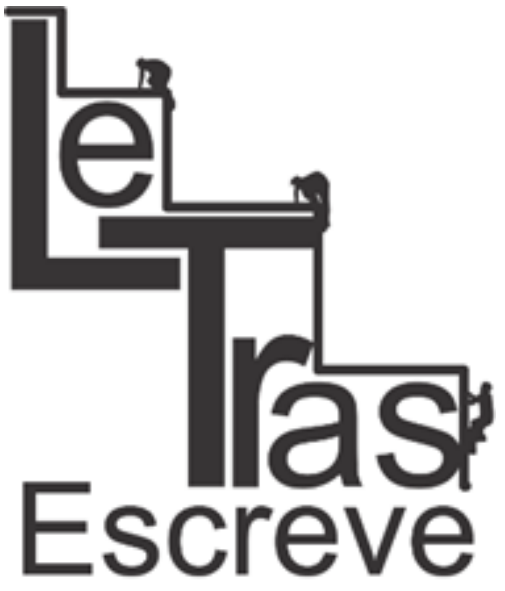

(ISSN 2238-8060)

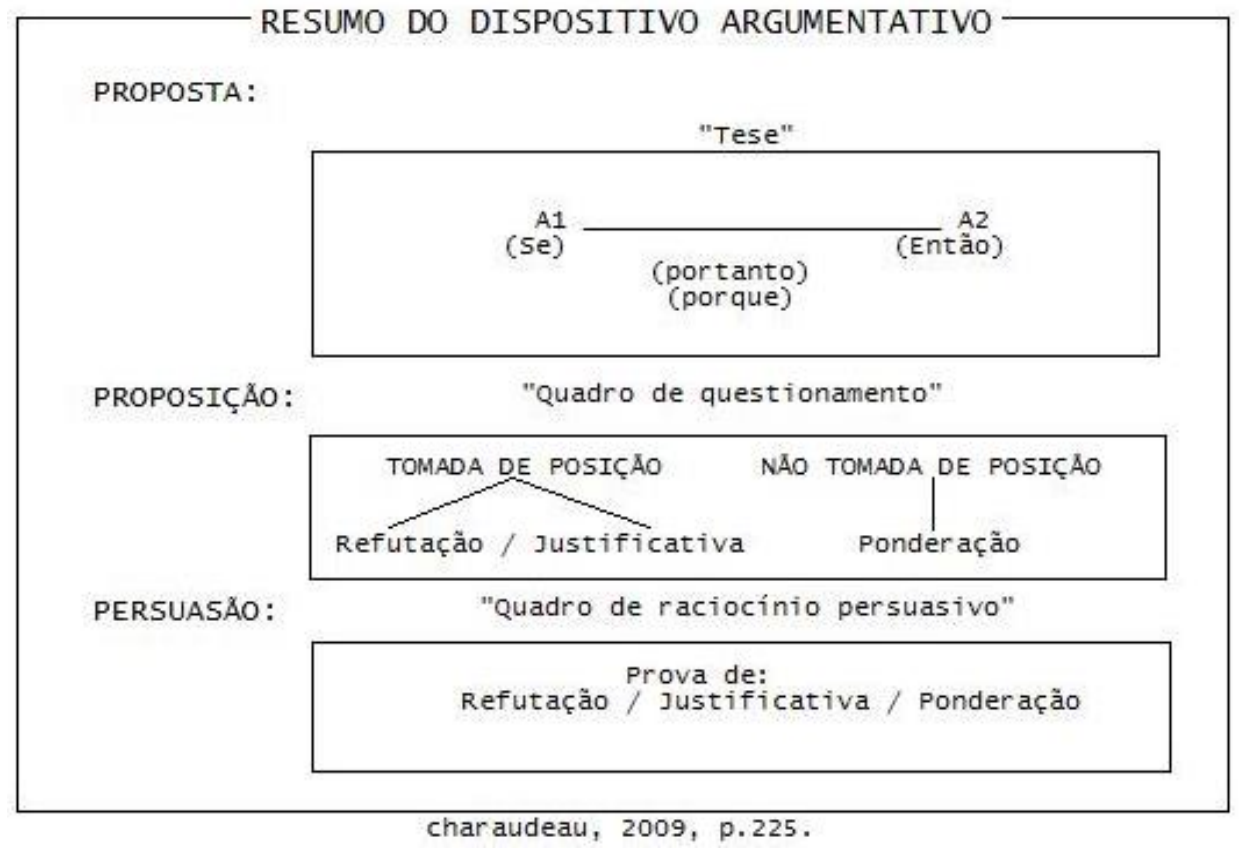

Como pode ser visualizado no quadro, o processo argumentativo se inicia com a elaboração da proposta, que será questionada quanto a sua veracidade pelo sujeito argumentante ao tomar seu posicionamento a favor ou contra a referida proposta, através da proposição. O processo argumentativo se completa quando o sujeito diz o porquê do seu posicionamento, nesse momento se argumenta e se constrói a prova da veracidade da proposta, mediante o ato de persuasão (CHARAUDEAU, 2009).

https://periodicos.unifap.br/index.php/letras

Macapá, v. 8, n. 2, 2 sem., 2018 


\section{Construção de sentido na charge jornalística}

As duas charges selecionadas para análise fazem alusão aos escândalos políticos que permeiam o cenário político brasileiro. A primeira charge, mais recente, faz alusão aos escândalos atuais relacionados aos desdobramentos da operação realizadas pela Polícia federal. Já a segunda, publicada há 7 anos, remete ao aniversário de 50 anos de Brasília, comemorado durante todo o dia de 21 de abril de 2010, na Esplanada dos Ministérios.

\section{Charge 1}

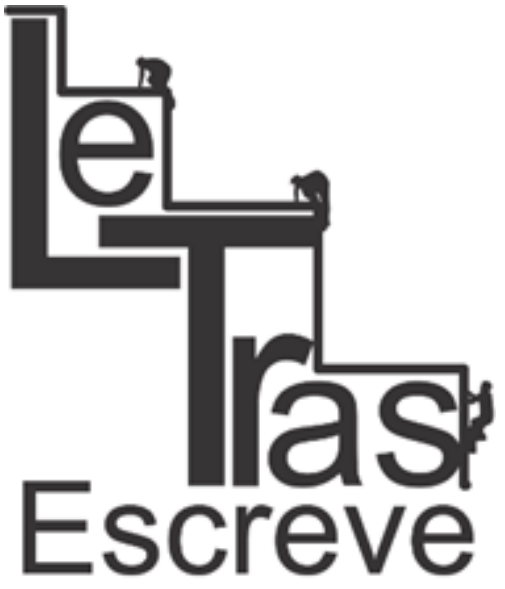

(ISSN 2238-8060)

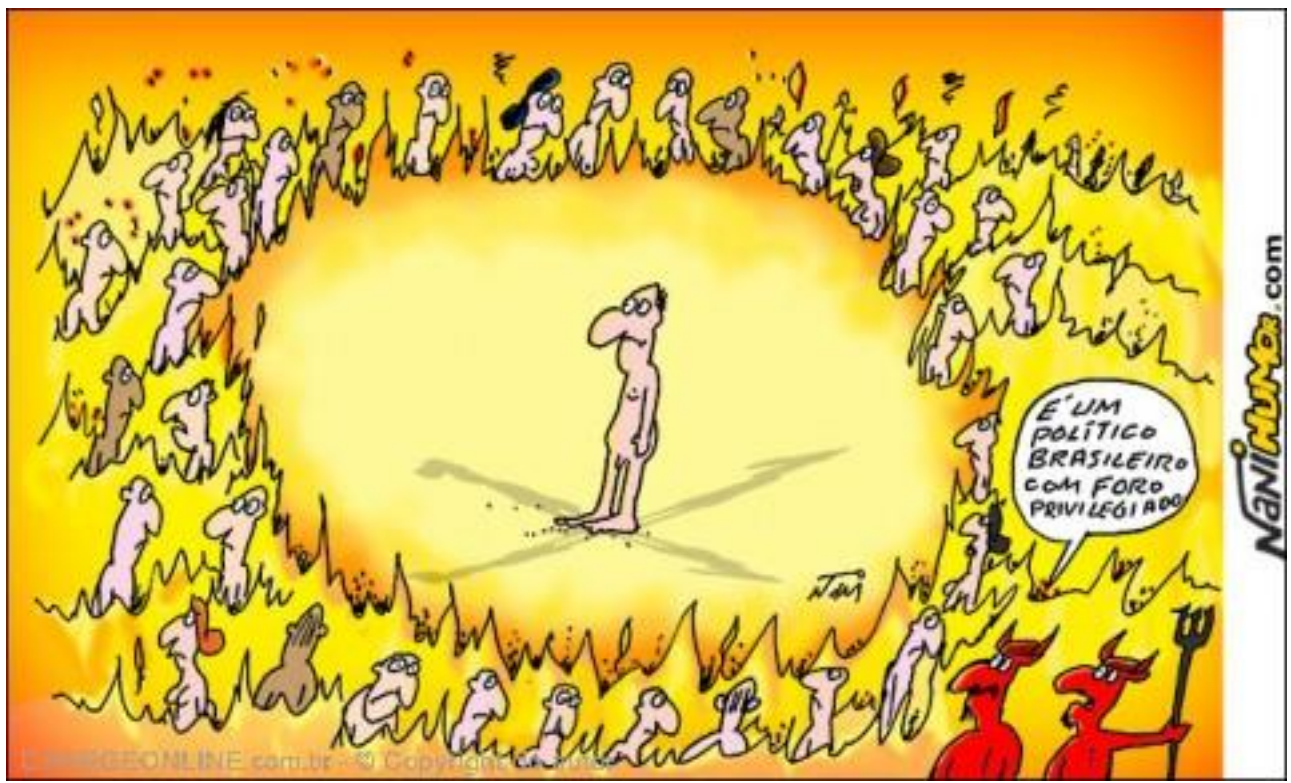

A charge online, 04/06/17

Referência: Denúncia do foro privilegiado do político brasileiro.

Objetivo: Criticar e ironizar a impunidade que impera do Distrito Federal, onde constantemente surgem denúncias sobre casos de corrupção, mas, na maioria das vezes, os políticos recebem concessões devido ao foro privilegiado. 
Relação intersemiótica ${ }^{4}$ na construção do sentido na charge: 0 verbal é essencial para o entendimento da charge. A linguagem nãoverbal também contribui sobremaneira para a contextualização da ação verbal ao revelar o político impune.

Recursos utilizados pelo autor: A afirmação de que o político brasileiro possui foro privilegiado. Essa afirmação, na verdade, é um pretexto para o chargista denunciar a impunidade do político. A imagem revela as chamas do inferno. A impunidade é associada ao foro privilegiado, evidência comprovada através da linguagem não-verbal, que também deixa claro, através da imagem do político livre das chamas.

Charge 2

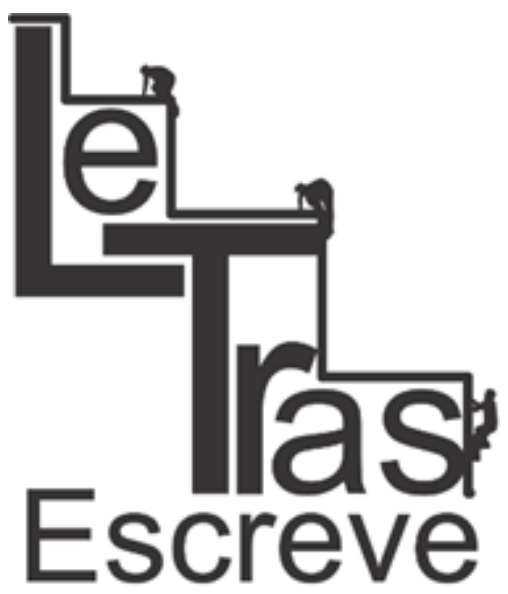

\section{BRASÍLIA - 50 ANOS "DANDO O BOLO" NO BRASILEIRO}

(ISSN 2238-8060)

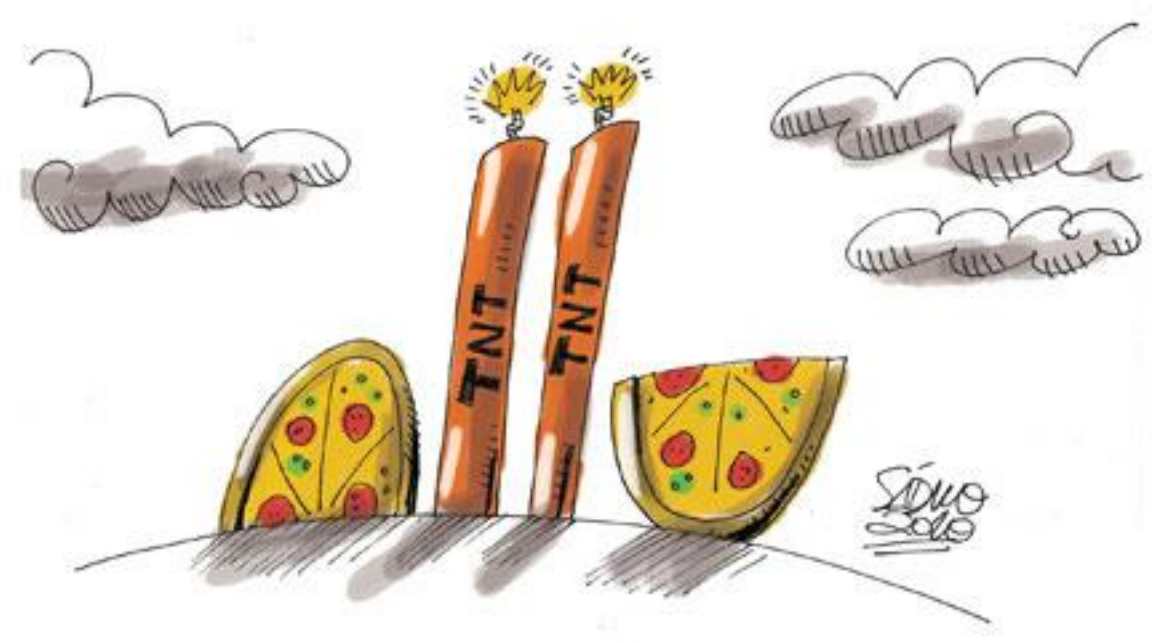

Jornal da Manhã , 25/04/2010

Referência: Comemoração do aniversário de 50 anos de Brasília.

Objetivo: Criticar, a partir do humor satírico e da ironia, a comemoração do aniversário de Brasília.

\footnotetext{
${ }^{4} \mathrm{O}$ termo intersemiose ou intersemioticidade é adotado como um fenômeno de encontro de linguagens (verbal e não-verbal) peculiar à charge.
} 
Relação intersemiótica na construção do sentido na charge: Predomina a linguagem não-verbal. O congresso nacional é representado pela imagem de duas bombas e pela imagem de duas metades de pizza, que fazem alusão à Câmara dos deputados e ao Senado. No entanto, a linguagem verbal, que aparece nos escritos TNT e no título são de fundamental importância para o entendimento da crítica proposta pelo chargista. Podemos afirmar que há a presença da metonímia, uma vez que a palavra Brasília é citada não necessariamente como a capital federal, mas, nesse caso, é tomada, também, pelos políticos que a compõem.

Recursos utilizados pelo autor: $O$ verbal utiliza-se do termo polissêmico bolo, que ao mesmo tempo lembra o bolo de aniversário

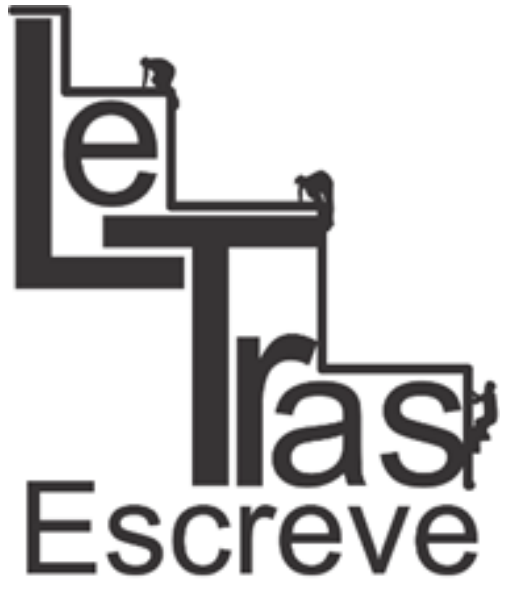

(ISSN 2238-8060) e a expressão dar o bolo ${ }^{5}$. Já a sigla TNT, que representa o composto químico trinitrotolueno, é um componente explosivo à base de tolueno e ácidos, muito conhecido pela sua potente ação explosiva. As bombas fazem alusão à expressão estourar, que significa vir à tona.

Muito utilizada quando a impressa noticia um caso de corrupção, como por exemplo na frase: "Estoura mais um caso de corrupção em Brasília". Observe-se o detalhe das bombas, através da cor amarelada percebemos que o pavio de ambas está aceso, o que significa dizer que estão prestes a estourar. Essa é a estratégia utilizada pelo chargista para deixar subtendida a dinâmica da capital federal, sempre estourando escândalos, inclusive no aniversário. O termo "Há 50 anos" deixa implícito essa constância. Enquanto a pizza remete à impunidade, visto já ter se tornado uma lexia a expressão "acabar em

\footnotetext{
${ }^{5}$ Segundo o Aurélio (2004 [eletrônico]) significa faltar um a compromisso. No caso do texto, faz alusão ao fato de Brasília (entenda-se os políticos), supostamente, de acordo com o chargista nunca ter comprido com suas obrigações de fiéis representantes do interesse dos cidadãos brasileiros.
} 
pizza"6.

Portanto, fica evidente que o teor crítico da charge só será desvelado e, por conseguinte, compreendido, se o leitor atentar para todos esses detalhes, usados como recursos expressivos, que subjazem às linguagens verbal e não-verbal.

\section{Encenação argumentativa na charge}

A charge, por se tratar de um gênero argumentativo, deve, de acordo com Charaudeau (2009) cumprir alguns quesitos, dos quais iniciamos com a própria proposta de argumentação do autor, para o qual a argumentação não se limita a uma sequência de frases e pro-

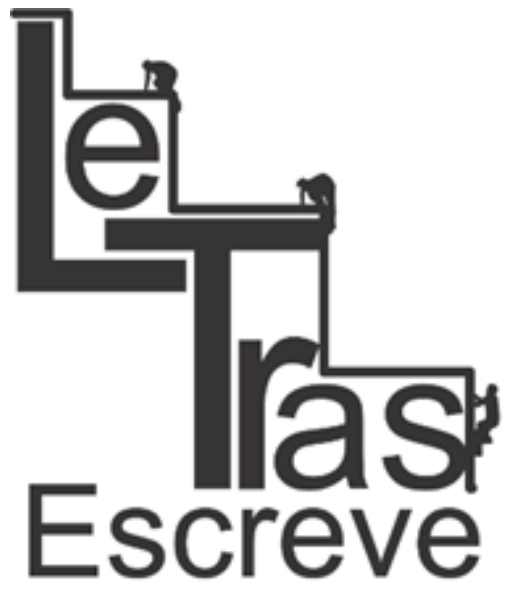

(ISSN 2238-8060) posições ligadas por conectores lógicos, o caráter argumentativo do discurso encontra-se mais frequentemente no que está implícito. Sendo assim, para que se constitua o discurso argumentativo, o autor postula que deve existir: uma proposta sobre o mundo que provoque um questionamento em alguém, quanto a autolegitimidade. Um sujeito que se engaje em relação a esse questionamento (convicção) e desenvolva um raciocínio para tentar uma verdade (quer seja própria ou universal), quer se trate de uma simples aceitabilidade ou de uma legitimidade quanto a essa proposta.

Quadro 4 - Encenação argumentativa da charge 1
\begin{tabular}{|l|l|}
\hline Proposta (tese) & $\begin{array}{l}\text { Quem comete atos ilícitos queima no inferno. O político brasileiro não } \\
\text { queima no inferno. }\end{array}$ \\
\hline $\begin{array}{l}\text { A proposição } \\
\text { (desenvolvimento } \\
\text { do ato persuasivo } \\
\text { destinado a provar } \\
\text { a veracidade da }\end{array}$ & \\
proposta) & \\
\hline $\begin{array}{l}\text { A persuasão (justi- } \\
\text { ficativa) }\end{array}$ & $\begin{array}{l}\text { Ideia estabelecida pelo chargista para produzir a prova da sua proposta } \\
\text { (tese). }\end{array}$ \\
\hline
\end{tabular}

\footnotetext{
${ }^{6}$ Segundo o Aurélio (2004 [eletrônico]) significa não resultar em nada.
} 
$\mathrm{Na}$ charge 1, o chargista elabora sua proposta (tese) ferindo a lógica esperada, ou seja, quem comete ato ilícito queima no inferno. Entretanto, o político brasileiro não sofre punição. A afirmação que é feita na charge a respeito do foro privilegiado dá origem à proposta e converte-se numa tentativa de levar o leitor a refletir sobre a condição de impunidade do político no Brasil. No momento em que o chargista se propõe a denunciar o político brasileiro, ele também prepara indícios para produzir a prova da sua proposta através do raciocínio persuasivo de que o caráter não prejudicial da ação de cometer atos ilícitos é decorrente da impunidade gerada com o foro privilegiado. Isso fica explícito por meio da linguagem verbal quando se afirma, categoricamente, que a não punição do político brasileiro se deve ao foro privilegiado. Assim como também fica explícita a mesma ideia por meio da linguagem não-verbal, pois a imagem revela o político longe das chamas do inferno, despreocupadamente.

Relação argumentativa da charge 1

Quem comete atos ilícitos queima no inferno

O político brasileiro não queima no inferno.

A1: Dado, premissa

A2: Conclusão.

(ISSN 2238-8060) Asserção de passagem:

(inferência): Onde impera o foro privilegiado, não há que se preocupar com a Justiça.

Prova-argumento: O político brasileiro é mantido longe das chamas do inferno.

Quadro 5 - Encenação argumentativa da charge 2.

\begin{tabular}{|l|l|}
\hline Proposta (tese) & Brasília completa 50 anos. São 50 anos "dando o bolo" no brasileiro. \\
\hline $\begin{array}{l}\text { A proposição } \\
\text { (desenvolvimento } \\
\text { do ato persuasivo } \\
\text { destinado a provar }\end{array}$ & $\begin{array}{l}\text { O desenvolvimento do ato persuasivo se dá através da linguagem não- } \\
\text { a veracidade da como recurso o chargista usa como cenário o Palácio do Pla- } \\
\text { proposta) }\end{array}$ \\
\hline $\begin{array}{l}\text { A persuasão (justi- } \\
\text { ficativa) }\end{array}$ & $\begin{array}{l}\text { Ideia estabelecida pelo chargista para produzir a prova da sua proposta } \\
\text { (tese). }\end{array}$ \\
\hline
\end{tabular}


Na charge 2, o chargista, fazendo uso de elementos semióticos verbais e não-verbais, satiriza o aniversário de Brasília e o símbolo político da capital federal, o Congresso Nacional. Ao mesmo tempo em que a proposta (tese) é evidenciada no título da charge, o chargista estabelece, através da linguagem não-verbal, subsídios que comprovam sua afirmação. Podemos pensar em uma refutação à proposta do tipo: "Não, não é verdade que foram 50 anos de corrupção e impunidade, porque sabemos que há também políticos honestos". No entanto, essa refutação não nega a proposta do chargista, porque, ao fazer alusão ao Congresso Nacional, utilizando bombas e pizza, ele não se propõe a negar a existência de políticos honestos. O que pretende deixar claro, e essa é a prova-argumento da sua proposta, é que escândalos estouram constantemente em Brasília, advindos de práticas ilícitas, e, o mais comum é que as investigações não sejam suficientes para punir os culpados, que acabam por não serem condenados ou são beneficiados com o foro privilegiado. No final, somente o cidadão brasileiro honesto sai perdendo.

Relação argumentativa da charge 2

(ISSN 2238-8060)

Brasília completa 50 anos

São 50 anos "dando o bolo" no brasileiro.

A1: Dado, premissa

A2: Conclusão

Asserção de passagem:

(inferência): A história de Brasília é marcada pela corrupção e pela resignação do povo brasileiro, que acaba sendo o maior prejudicado nesse esquema de corrupção.

Prova-argumento: Mais um escândalo está prestes a "estourar", basta atentarmos para as bombas acesas, indicando a perpetuação de escândalos e de impunidades.

Em ambas as charges, a linguagem não-verbal é o ponto prin- 
cipal do raciocínio que conduz o fio argumentativo do chargista. É interessante observar que o fazer argumentativo no gênero em questão tende a ocorrer, frequentemente, de maneira implícita. Ao se referir a situações dessa natureza, Charaudeau (2009) diz que nem sempre combinações frásticas comportam marcas explícitas de operação lógica, ademais, ressalta que o aspecto argumentativo de um discurso encontra-se, muitas vezes, no que está implícito. Dessa maneira, para que o leitor seja capaz de desvelar os referidos argumentos, faz-se necessário atentar para as pistas imagéticas fornecidas pela linguagem não-verbal.

\section{Considerações finais}

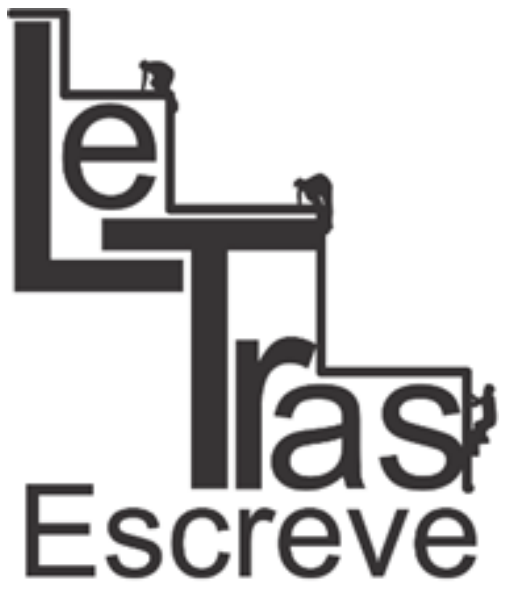

A análise semioliguística da charge revelou a relação de interação dialética entre discurso e sociedade. Comprovou-se também que essa relação constitui a base do texto chárgico para elaboração da encenação argumentativa que tem como meta satirizar associando, por vezes, o humor satírico ao deboche e à ironia.

A sátira revela que, dia após dia, os políticos cometem crimes (ISSN 2238-8060) de corrupção, mas permanecem no poder, restando ao povo brasileiro uma resignação forçada de quem gostaria (mas não acredita) de que um dia tudo não "acabe em pizza". Embora o cenário nacional dê sinais de mudança em relação às investigações realizadas pela polícia federal, o direito dos políticos brasileiros ao foro privilegiado torna esse processo investigativo repleto de regalias.

\section{Referências}

CHARAUDEAU, P. Discurso das mídias. Trad. Ângela S. M. Corrêa, São Paulo: Contexto, 2007. 
CHARAUDEAU, P. Linguagem e discurso: modo de organização. Trad. Ângela S. M. Corrêa e Ida Lúcia Machado. São Paulo: Contexto, 2009 FIORIN, J. L. Linguagem e ideologia. São Paulo: Ática, 1988 .

ROMUALDO, E. C. Charge jornalística: intertextualidade e polifonia: um estudo de charges da Folha de São Paulo. Maringá: Eduem, 2000. TEIXEIRA, L. G. S. Sentidos do humor, trapaças da razão: a charge. Rio de Janeiro: Edições Casa de Rui Barbosa, 2005.

VALENTE, André. O processo de criação das charges. In: AZEREDO, J. C. (org.). Letras \& Comunicação: uma parceria no ensino de Língua Portuguesa. Rio de Janeiro: Vozes, 2001.

Enviado em: 12/06/2017

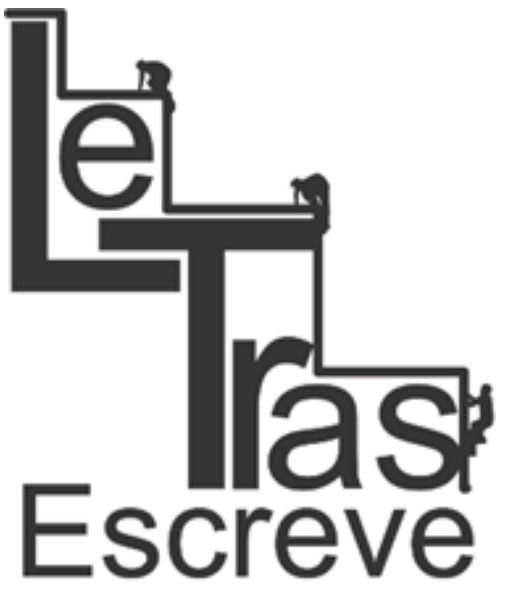

Aceito em: 13/03/2019

(ISSN 2238-8060) 